\title{
Orçamento participativo Conciliando direitos sociais de cidadania e legitimidade do governo
}

\section{Emil A. Sobottka ${ }^{l}$}

O Orçamento Participativo, implementado pela Frente Popular em Porto Alegre, e posteriormente extendido a um grande número de cidades e ao estado Rio Grande do Sul, é um fenômeno que, a despeito de muitas análises já feitas (cf. Avritzer e Navarro, 2003, bibl.), continua com importantes facetas insuficientemente refletidas. $\mathrm{O}$ que aqui se propõe é abordá-lo num duplo sentido: como uma possível oportunidade política para segmentos que buscavam assegurar pela via legal a conquista de direitos sociais de cidadania, e como instrumento político dos gestores em busca de legitimidade num contexto adverso. Em ambos os casos se verificará como os agentes necessitam equacionar a questão da tensão entre legitimidade e legalidade de suas aspirações e ações.

\footnotetext{
${ }^{1}$ Doutor em Sociologia e Ciência Política pela Universidade de Münster, Alemanha, e professor na Pucrs. Agradeço aos participantes do seminário Movimentos sociais e direitos de cidadania: uma comparação Brasil-RFA, do Projeto Probral (Pucrs e Universidade de Kassel), pelos comentários e sugestões. Endereço: sobottka@ pucrs.br
}

Civitas, Porto Alegre, v. 4, nº 1, jan.-jun. 2004 


\section{Bem-estar social ou estado mínimo?}

Quando a coligação capitaneada pelo PT e autodenominada Frente Popular assumiu o poder na prefeitura municipal de Porto Alegre, em 1989, havia um momento político-social de disputa pelo modelo de sociedade e de estado no País. Enfrentavam-se nesta disputa os portadores sociais de um projeto de bemestar social, com amplos direitos sociais de cidadania assegurados pelo estado, por um lado, e os portadores do projeto de sociedade em que o máximo possível de relações fossem reguladas pelo mercado e sem ingerência do estado, por outro. Este período teve seu auge nos meses que separam a promulgação da nova Constituição em setembro de 1988 e a posse de Fernando Collor de Mello em março de 1990.

Recém havia sido concluída, sem rupturas, a transição do regime militar à democracia, culminando com a promulgação da nova Constituição Federal. Coroava-se assim um processo no qual a sociedade civil se contrapôs ao regime ditatorial e construiu espaços de participação, seja através de eleições, de reconquista de liberdades fundamentais como a de imprensa, ou através de sua auto-organização em sindicatos, associações e movimentos sociais. Em especial durante o processo constituinte, alguns segmentos da sociedade foram exitosos em seu propósito de inscrever no texto constitucional um vasto conjunto de pleitos que, a seu juízo, seriam direitos dos cidadãos face ao estado.

Os movimentos sociais populares, ${ }^{2}$ que se constituíram desde os anos 1970 no interior do regime militar, tiveram sua consolidação como agentes de identidade própria e com capacidade de articulação para, através de diversas formas de participação, poder influenciar em pontos específicos a definição de políticas sociais. Segundo Fleury (1994, p. 221), “a democratização é assumida por estes movimentos como condição imprescindível para a melhoria de suas condições de vida, na medida em que o instrumento que lhes pode garantir a sua capacidade de pressão é sua experiência de organização e de participação".

Buscou-se realizar no Brasil, no curto espaço de aproximadamente uma década, a (re)introdução simultânea dos direitos civis, políticos e sociais, as clássicas três gerações de direitos - tarefa que em países como a Inglaterra levou três séculos. Mas essa expansão, em especial a dos direitos sociais de cidadania, logo seria revelada como ambígua: entre a inscrição de direitos na Constituição e a garantia efetiva de seu benefício abria-se um abismo - e os

\footnotetext{
${ }^{2}$ A qualificação de "populares" é usada aqui num sentido restritivo, para movimentos sociais orientados à realização material ou à ampliação de direitos sociais de cidadania. Pelos movimentos sociais resistentes à mudança, a relação com o governo via de regra é cultivada através de mediações personalizadas, distintas daquelas tratadas neste texto.
} 
mecanismos institucionais disponíveis à época não seriam capazes de superá-lo (cf. Sarlet, 2003; Sobottka, 2000). Este foi um dos fatores que levou os movimentos sociais populares a apostarem decididamente na conquista do poder do estado pela via democrática, para poder efetivar os direitos formalmente assegurados a partir da gestão do estado.

O confronto dos dois projetos de sociedade pela via eleitoral, no período assinalado, cristalizou-se em dois momentos: nas eleições de 1988 e de 1989, com resultados distintos. Na primeira delas foram eleitos, tanto em Porto Alegre como em outras cidades, muitos prefeitos de partidos considerados de esquerda, portadores do projeto ampliador de direitos sociais. Considerando-se o número de votos, houve um equilíbrio relativo entre os dois projetos; a diferença é que em relação aos pleitos anteriores, os partidos considerados de esquerda haviam ampliado seu apoio em detrimento dos partidos representantes dos grupos já no poder (cf. Fleischer, 2002; Nicolau, 1998). Esta vitória relativa animou os partidários da oposição, que passaram a nutrir expectativa de vitória de seu candidato nas eleições presidenciais do ano seguinte expectativa esta que, com se sabe, foi frustrada.

Mais do que a derrota eleitoral, o resultado daquele segundo pleito em favor de Fernando Collor de Mello foi, em nível nacional, a derrota do modelo de expansão de direitos sociais e da utopia de uma nova sociedade. Já desde o processo constituinte, mas muito mais após a definição clara do confronto entre os projetos nacionais, estava colocado um dilema para as elites políticas vencedoras, que foi assim definida por Fleury (1994, p. 232): “abrir o jogo político de forma a incorporar a experiência e as demandas dos setores populares organizados, sabendo que isso implica administrar diferentemente a distribuição dos recursos escassos, ou relegar essa massa periférica a uma situação de deserdados sociais, o que representa o fortalecimento de uma sociedade dual". A opção foi claramente no sentido de conter as demandas materiais, fortalecendo o pólo da reforma focalista, que num contexto de democracia formal restringe as políticas sociais à assistência localizada, assegurando não o conjunto de direitos inscritos no texto constitucional, mas mínimos sociais (cf. Lopes, 1998; Sposati, 1997). Vieira denomina o período posterior a 1988, coroado com a vitória nas eleições presidenciais, como sendo o de política social sem direitos sociais (Vieira, 1997).

Frustrou-se, assim, a expectativa de amplos setores da população brasileira de ampliarem seus direitos materiais de cidadania e de realizarem profundas transformações sociais dentro das vias democráticas, implementando um projeto de bem-estar social que materialize direitos sociais de cidadania. Quando o candidato derrotado em 1989 vence as eleições doze anos mais tarde, sua base eleitoral, seu programa de governo e, em especial, as condições 
sociais e econômicas para projetos alternativos não eram mais as mesmas.

\section{O desafio de governar}

Antes de consumar-se a derrota deste projeto ao nível nacional, no entanto, vitórias nas eleições municipais de 1988 em Porto Alegre, São Paulo e muitas outras cidades alimentaram a esperança dos seus portadores. O crescimento expressivo do apoio às oposições manifesto nas urnas fez crer que dela se esperava uma nova política.

Com aquela vitória eleitoral, alguns partidos de oposição, em especial o Partido dos Trabalhadores e seus aliados, pela primeira vez haviam sido colocados diante do desafio de deixar a oposição para administrar um conjunto de cidades importantes no País. ${ }^{3}$ Necessitavam encontrar formas de traduzir ao cotidiano da gestão pública sua proposta de inverter as prioridades de governos anteriores, de ser diferentes dos outros partidos no trato da coisa pública, de assegurar os direitos sociais daqueles que historicamente eram relegados a segundo plano, e de transformar profundamente a sociedade atual. Repousava sobre eles a expectativa de que seriam finalmente materializados os direitos formalmente incorporados ao projeto de sociedade durante o processo constituinte, mas faltava experiência administrativa para uma gestão local capaz de corresponder a esta expectativa.

O PT tem reagido à situação como um todo mediante a realização de seminários, fóruns de discussão e programas de formação. As parcas experiências de gestão pública e os muitos sonhos de uma sociedade melhor encontraram eco nestes eventos e foram traduzidos num conjunto de textos trazidos a público como sendo o modo petista de governar. No limite, segundo acalentado por alguns dos seus formuladores, este modo de governar poderia inclusive constituir-se em uma forma alternativa de transição, pela via democrática, ao socialismo. A ênfase, no entanto, estava em governar para os segmentos até então preteridos, em consonância com o que teria sido o mandato recebido através das urnas.

Ao descrever este desafio para seus correligionários de partido, o então secretário para assuntos institucionais, Jorge Bittar (1992), admitiu que tinha havido uma maximização de objetivos pelo partido ao serem assumidas

\footnotetext{
${ }^{3}$ Cf. Kinzo (2004). Costa (1997) mostra, com base em pesquisa realizada em Minas Gerais, que mesmo partidos estabelecidos como PMDB precisaram encontrar novas formas para a gestão pública, em especial a municipal. Em Uberlândia, Juiz de Fora e Governador Valadares foram implementados, já no início dos anos 1980, modelos de gestão pública em que a participação da sociedade civil era muito incentivada. O próprio Partido dos Trabalhadores já havia vencido eleições municipais em cidades como em Fortaleza e Diadema, mas agora o número e o porte das cidades era bem maior, aumentando a responsabilidade.
} 
reivindicações dos movimentos sociais como a estatização dos transportes e do sistema de saúde, a democratização do acesso ao ensino público, o uso social do solo urbano e a formação de conselhos populares. Ele expressava assim o reconhecimento de que face às vitórias nas eleições os objetivos partidários de longo prazo -expressos sinteticamente na máxima da implantação do socialismo pela via democrática- necessitavam de uma mediação política que viabilizasse a gestão pública do município dentro das condições concretas da realidade brasileira. Na busca desta mediação foi que emergiu aquele conjunto de proposições definido como modo petista de governar, que, sinteticamente, se compõe dos seguintes pontos:

- necessidade de alterar o próprio modo de legitimação do poder político local, baseando-o numa cultura política dos direitos coletivos e individuais;

- fortalecimento político real do Legislativo e desmonte dos procedimentos que transformam os vereadores em despachantes do Executivo;

- reconhecimento do caráter estratégico da ética para afirmação de uma política transformadora, resgatando o mais absoluto respeito à moralidade no trato da coisa pública;

- instituição do direito à participação, combinando elementos da democracia representativa aos da democracia participativa, aprofundando as formas de controle da sociedade sobre a prefeitura (ibid., p. 25).

Este novo programa de governo municipal procurou manter as teses historicamente defendidas pelo partido, conciliando-as com as exigências cotidianas de uma gestão pública, sem desconsiderar a permanente necessidade de manter e, se possível, ampliar a legitimidade junto aos eleitores. O propósito declarado, no entanto, não era apenas o de gerir bem, mas de reformar estruturalmente a forma local do estado. Nesse sentido, o mesmo documento enumera os traços centrais da pretendida reforma:

participação popular para garantir a realização do plano de governo e assegurar uma mudança na correlação de forças entre "classes populares e dominantes" a partir da ocupação de espaços no aparelho estatal;

$\square$ inverter as prioridades de governo, garantindo o direcionamento dos investimentos para áreas consideradas mais carentes, recuperando a qualidade do serviço público e garantindo igualdade de acesso aos serviços básicos a todos;

- partindo de uma concepção de que o estado havia sido capturado por interesses privados, buscar desprivatizar, democratizar e tornar público o estatal, além de combater o clientelismo e a corrupção; 
- politizar a distribuição dos recursos públicos oriundos da arrecadação de impostos na forma de conflito público com opositores políticos relacionado-a ao projeto nacional;

- praticar uma política de alianças que garanta a sustentação política e social do governo, inclusive envolvendo o legislativo municipal (Bitar, 1992, p. 22).

O PT optou por aprofundar a descentralização ao seu modo, abrindo a gestão pública a setores antes relegados à apatia, à cooperação clientelista ou à reivindicação organizada em movimentos sociais. Pensou-se que esta participação seria equacionada tranquilamente como uma co-gestão com uma adequada divisão de tarefas, assim expressa: "Há aquelas tarefas que cabem aos movimentos sociais, como criair espaços autônomos de organização e formas próprias de institucionalização de suas representações. Ao Executivo, cabem aquelas ações de governo para democratizar, incorporar a participação popular no processo de decisão e de planejamento, promover e ampliar as formas de consulta à sociedade civil." (ibid., p. 23)

A expectativa dos novos governantes com a co-gestão e a descentralização foi que o movimento popular se fortalecesse para contribuir como fiel na balança do poder, dando governabilidade e legitimidade à ação do governo local. Assim permitiria que este colocasse em prática políticas voltadas para segmentos da população antes relativamente excluídos das políticas públicas das cidades. Para os movimentos sociais e outros portadores do projeto de uma nova sociedade parecia haver chegado a hora de dar grandes passos em direção ao objetivo. Nesta parceria, especialmente com relação à co-gestão, no entanto, havia uma ambigüidade: a participação oportunizada exige níveis de formalização e coloca como necessários lógicas, cronogramas e procedimentos típicos da burocracia ou do jogo político, alheios ao cotidiano dos movimentos e dos cidadãos antes desmobilizados.

Em Porto Alegre, o Orçamento Participativo foi estilizado como o lugar por excelência da participação descentralizada definida como co-gestão e como marca distintiva do modo petista de governar. Presta-se, por isso, para refletir sobre a possibilidade de servir como via de acesso aos direitos sociais de cidadania para os movimentos sociais e como instrumento de legitimação dos governantes.

\section{Orçamento participativo: um processo de cidadania}

A eleição da Frente Popular em Porto Alegre deu-se, como referido acima, no interregno entre a promulgação da nova constituição e as eleições 
presidenciais de 1989. À disputa entre projetos diferentes de sociedade somava-se uma resistência explícita do governo federal a colocar em prática parte importante das mudanças pactuadas no processo constituinte - entre elas muitos dos direitos sociais.

Porto Alegre era uma cidade que podia orgulhar-se de uma longa tradição associativa (Silva, 2002). Movimentos de moradores, associações de bairro e movimentos sociais condensavam aspirações de um grande número de cidadãos. E, naquela eleição de 1988, muitos deles encontraram nas propostas feitas pela Frente Popular em sua campanha uma representação destas aspirações e passaram a acreditar que, eleita, teria condições de implementar reformas abrangentes com vistas a uma sociedade mais igualitária e à garantia ampla de direitos sociais de cidadania. A importância desta expectativa não pode ser subestimada, porquanto muitos estavam vendo crescentemente frustrada em nível nacional, já durante o governo de transição à democracia, de José Sarney, a aspiração de reformas profundas, em especial a materialização de direitos sociais nos termos da Constituição. $\mathrm{O}$ argumento do governo federal à época era que muitas das reformas previstas -como transferências de arrecadação para estados e municípios, ampliação de direitos materiais de cidadania- tornariam o país ingovernável.

Quando um amplo conjunto de movimentos e organizações da periferia econômica, social e geográfica da cidade apóia um partido político -ou uma frente, como neste caso-, eles o fazem porque associam uma expectativa a esta possível tomada do poder. Ademais, é intrínseco ao jogo do poder político que o partido ou a frente, após assumir o seu mandato, tenha que dar algum tipo de satisfação a esta sua base. Portanto, pode-se perguntar qual a relação existente entre as expectativas dos movimentos e organizações e a gestão municipal da Frente Popular em Porto Alegre.

Como a estratégia seguida pelos movimentos nos anos precedentes foi a de assegurar nos textos legais um amplo conjunto de demandas como direitos, pode-se supor que eles esperavam dos novos gestores a materialização destes direitos. Mas será que a Frente Popular tinha a possibilidade de cumprir estas expectativas?

Há razões para ser cético: o estado moderno, desde a própria origem, abriga uma contradição lógica que limita suas possibilidades de dar materialidade a direitos sociais de cidadania. Flickinger, ao expor as contradições da lógica liberal que rege os sistemas jurídicos ocidentais na atualidade, mostrou muito bem as dificuldades inerentes à expectativa de que o estado de direito garanta a materialidade de direitos de cidadania (Flickinger, 2003; 2004). Segundo este autor, a ação do estado é legitimada por lei, cabendo-lhe garantir a ordem legal e impedir atividades perturbadoras da ordem pública, restringindo sua ação ao 
espaço definido legalmente. Ao garantir para o cidadão um conjunto de direitos consistentes basicamente de liberdades, este estado não leva em consideração interesses materiais em jogo. Mais que isto: neste estado, onde a liberdade é o princípio organizador do mundo sociopolítico, o direito é empregado como mediação para organizar e proteger a articulação e a concretização da livre vontade humana sob a condição de abstrair completamente as condições materiais ou motivações dos indivíduos. O estado assim formado pode simultaneamente assegurar a liberdade individual e dar espaço ao desenvolvimento da desigualdade material.

A resposta clássica a esta contradição lógica do estado liberal tem sido construída em etapas e desembocou no assim chamado estado de bem-estar social. Num primeiro momento, o estado incentivou a auto-organização da sociedade civil no sentido de assegurar os direitos materiais mediante uma rede de seguridade, concretizada através de iniciativas que via de regra tinham caráter mutual e residualmente eram compensadas pela filantropia piedosa e pela solidariedade familiar ou vicinal. Com a crescente segmentação social, muita gente ficou fora destas redes de seguridade, obrigando o estado a agir. Segundo Flickinger, a ação do estado implicou na necessidade de juridificar os direitos, deslocando a questão social para a esfera da política, criando um complexo de instituições agregadas ao estado clássico, transformando-o em estado de bem-estar social. ${ }^{4}$ Com essa juridificação, crescente quantidade de demandas foram acolhidas como direitos. Mas o sistema foi incapaz de converter as demandas em benefícios materiais sem aprofundar suas contradições.

Marshall também já tinha apontado para a contradição entre a expansão de direitos sociais e a proteção do indivíduo contra o estado. Esta contradição, para o autor, faz com que o exercício da cidadania social entre em conflito com as condições necessárias para o capitalismo (Marshall, 1967).

A estratégia de juridificação de demandas em direitos presente no processo constituinte brasileiro baseava-se, pois, num modelo de estado já há muito em crise - crise que está latente como contradição em sua própria origem (Flickinger, 2003) e que foi aguçada por equívocos estratégicos em sua implementação, como a excessiva vinculação dos direitos sociais ao trabalho (cf. Offe, 1991). Ademais, a Frente Popular tinha recebido um mandato para governar tão somente uma cidade onde, a despeito de incipiente processo de descentralização, a arrecadação e a definição das políticas são restritas (cf.

\footnotetext{
${ }^{4}$ Tomando como referência princípios de justiça, Offe (2002) evoca a imagem de um edifício como figurativa para esta gradativa ampliação dos direitos, sobrepondo-se novos patamares aos pisos até então existentes. As reformas sociais atuais seriam análogas a uma reforma em todos os andares.
} 
Almeida, 1996). Nas condições vigentes no Brasil, não havia a possibilidade de se estabelecer uma cidade do bem-estar social.

A saída encontrada em Porto Alegre foi a implantação do Orçamento Participativo, que, juntamente com outras iniciativas, encetou um processo de cidadania. Processo de cidadania é aqui entendido como constituição de uma rede de relações no contexto de uma luta entre grupos e classes sociais, em que direitos e deveres de cidadania são socialmente definidos e sua implementação disputada. Era a resposta dos novos governantes municipais à oferta de cooperação feita por uma parte significativa de sua base política.

Segundo Avritzer (Avritzer e Navarro, 2003), são necessárias pelo menos quatro condições para que semelhante processo possa ser implementado: vontade política dos governantes atuais, uma ampla densidade associativa que expresse coesão e organização da comunidade local, uma concepção institucional e, por fim, capacidade administrativa e financeira para implementar a proposta. Especialmente com relação às primeiras duas condições há que se observar que a implantação do Orçamento Participativo e de outras iniciativas como os congressos da cidade representou a tentativa de sair do modelo liberal representativo para o modelo republicano de participação, sobretudo rousseauniano, de relação estado-sociedade. O processo de cidadania expressa condensadamente esta mudança.

Este processo de cidadania não supera a contradição intrínseca à crescente juridificação de demandas. Ele não elimina o conflito entre cidadania social e as condições necessárias ao capitalismo na cidade, mas amplia o espaço político para a negociação e devolve aos grupos sociais interessados a responsabilidade pelo cumprimento ou pela frustração das expectativas. Com isso desloca o eixo de manifestação da contradição do direito para a arena política.

Inicialmente havia indicativos de que aquilo que ali se gestava se aproximaria da construção de um espaço do Político, no sentido que Flickinger (2004) defende, com base numa releitura de Carl Schmitt. Corroboravam neste sentido tanto o fato de que o Orçamento Participativo era um processo informal, prévio à elaboração do projeto de lei orçamentária pelo poder executivo local (cf. Sobottka et al., 2004), como a insistência na participação de movimentos sociais e associações de moradores nas assembléias. Observações recentes dão conta que hoje a participação é sobretudo individualizada, e o processo, como tal, está altamente rotinizado, com detalhamento pormenorizado tanto da vida ad intra como dos critérios para a alocação de recursos. Para participar é preciso submeter-se às regras veladas pelo poder executivo. 
Aqui não há condições de detalhar em cifras o quanto este modelo de cooperação cívico-estatal satisfaz as expectativas dos movimentos e organizações sociais. Alguns resultados para eles saltam à vista, como a expansão da infra-estrutura e a melhoria de diversos serviços públicos. Nas duas pontas do orçamento, a prefeitura implementou medidas claramente redistributivas: através de forte aumento de impostos e taxas como Iptu, Issqn, taxa de lixo e iluminação pública, por um lado, e de expansão da infra-estrutura e a alocação de equipamentos públicos em áreas onde vive a população mais pobre. Por outra parte, a despeito de uma continuada política de legalização de ocupações de terrenos urbanos, da expansão da rede escolar municipal e da implantação de um programa de renda mínima que atinge aproximadamente 1.250 famílias, os direitos individuais de cidadania ocupam um lugar secundário na nova política.

Para a democracia local o Orçamento Participativo contribuiu ao diminuir muito as barreiras para a participação dos cidadãos na política de sua cidade, ao qualificar militantes dos movimentos em processos de disputa política e ao inverter a hierarquia da participação: enquanto antes os segmentos mais ricos participavam mais e os mais pobres permaneciam praticamene alijados, agora a situação é inversa. ${ }^{5}$

Mas se os movimentos e organizações sociais tinham suas razões para aderirem e - a julgar pelo resultado das eleições municipais que se seguiram, nas quais a Frente Popular foi reiteradamente reconduzida ao poder- para permanecerem como parceiros no processo de cidadania, também os partidos governantes reunidos na Frente Popular têm tido suas razões para dele participarem. Uma destas razões que não pode ser subestimada é a necesidade de legitimação.

\section{Orçamento participativo e legitimidade política}

Ao assumir o poder em Porto Alegre, a Frente Popular deparou-se com um dilema: havia prometido a seus eleitores que inverteria as prioridades da gestão pública, mas estes mesmos cidadãos que deram vitória à Frente, deixaram-na com uma minoria acanhada no parlamento local - 11 das 33 cadeiras da Câmara de Vereadores. Como então inverter prioridades sem ter apoio majoritário na casa legislativa, a quem cabe também legislar sobre o orçamento?

Mesmo que não tenha sido de todo planejado em sua abrangência, o

${ }^{5} \mathrm{Cf}$. as diversas contribuições presentes em Verle e Brunet (2002). 
Orçamento Participatio, que emergiu da primeira proposta de consulta popular sobre as prioridades para os investimentos da prefeitura municipal, foi uma busca de legitimidade supra-jurídica para a anunciada inversão de prioridades; foi uma fuga para frente num contexto em que a via legislativa tradicional estava virtualmente bloqueada.

Legitimidade é geralmente entendida como aceitação e apoio das iniciativas e ações do governo. Enquanto a falta com a legalidade pode ocasionar ao governante a sanção direta, prevista para os casos de descumprimento da lei, a conquista ou perda da legitimidade verifica-se mediatamente e pode não apenas dar-se em graus variados como também distribuir-se no tempo.

Andrew e Goldsmith (1998) mostraram como a legitimidade de governos locais vem decaindo nas últimas décadas. Para eles, este declínio se deve a vários fatores como: crise das instituições políticas, corrupção, crise do modelo de estado centrado no bem-estar social. Mas há ainda dois outros fatores de enorme abrangência, relacionados com recentes reformas políticas. Em muitos países, dentre os quais estes autores destacam a Grã-Bretanha, foram implementadas nas décadas de 1980 e 1990 reformas abrangentes na política local, com privatizações e terceirização de serviços (cf. Johnston, 1996). Um efeito imprevisto disto foi uma comoditização dos serviços públicos. Paralelamente, a mesma reforma incentivou uma mudança no trato dispensado pelas administrações públicas municipais aos que necessitam de seus serviços, passando a tratá-los como clientes. Com isso, valores de cidadania foram substituídos pelos valores de consumidor. Ora, face a serviços públicos comoditizados, o cidadão-cliente torna-se exigente, mas esbarra nas limitações da administração pública em possibilitar-lhe o exercício de suas preferências, o que tem como efeito a insatisfação deslegitimadora.

Como resposta, estes autores propõem a retomada da cidadania local; em sua opinião, ela não deveria ficar restrita aos aspectos civis e políticos, mas incluir também os aspectos locais. Cidadania local significaria a possibilidade da construção coletiva de um espaço no qual a pertinência e a relação com a cidade poderiam ser debatidos e deliberados. Para eles, o senso de cidadania emerge dos próprios debates e compromissos travados entre indivíduos e grupos; mas a cidadania local exige que no nível local não apenas sejam executadas, mas também deliberadas políticas públicas correspondentes. Nesse sentido, a cidadania local teria estatuto comparável ao da cidadania nacional, não podendo ser eruída pelas autoridades centrais.

O processo de cidadania instaurado com o Orçamento Participativo em Porto Alegre tem muitos traços desta cidadania local. Não obstante a consulta à população para definir as prioridades para os investimentos estar prevista na Lei Orgânica do Município de Porto Alegre (art. 116) e corresponder às 
tendências internacionais à descentralização, para ela confluíram motivos constituintes do modo petista de governar. Seu início foi modesto e marcado por improviso (Fedozzi, 1997; 2000). Só ao longo da realização das primeiras consultas ele recebeu o nome de "orçamento participativo".

Uma vez implementado, o Orçamento Participativo municipal em Porto Alegre foi objeto de diversas iniciativas e intenso debate sobre sua legalização. Pode-se dividir as iniciativas, segundo seus propósitos, em dois grandes grupos: de um lado, aquelas que queriam tornar o processo perene, assegurar sua continuidade mesmo sob a gestão de outros partidos; de outro, aquelas que queriam dissociar o Orçamento Participativo do Partido dos Trabalhadores, líder da Frente Popular.

Em ambas propostas argumentou-se estar em busca de autonomia do Orçamento Participativo: uma parte da Frente Popular queria dar-lhe autonomia para protegê-lo do risco de descontinuidade em caso de alternância de partidos políticos na prefeitura; a oposição buscava a autonomia deste processo consultivo frente ao Partido dos Trabalhadores, visto como tutor do processo. Ironicamente, no interior da Frente Popular, aqueles que se opunham à legalização também tinham na autonomia a base de seu argumento: segundo eles, a autonomia existente, inclusive para autoregulamentar-se, se perderia ao permitir que a Câmara de Vereadores impusesse regras ao processo.

Como bem mostrou Dias (2002), as posturas majoritária pró e contra a legalização se alternaram no bojo do jogo político entre oposição e situação mais do que com base em fidelidade ao princípio da autonomia. Isso fica claro logo na primeira rodada deste jogo, perto do final do primeiro mandado: face à dúvida sobre as possibilidades de recondução a um segundo mandato, o próprio Executivo iniciou o debate e levou à formulação de propostas situacionistas em favor da legalização, para mudar de postura tão logo divisou na recondução ao poder a garantia de continuidade do Orçamento Participativo com maiores conveniências partidárias do que na legalização. Em rechaço às iniciativas da oposição, que paralelamente mudou de posição de majoritariamente contrária a favorável à legalização, desde então vêm sendo utilizados básicamente dois expedientes pela Frente Popular: retardar a tramitação de eventuais projetos e insistir na inconstitucionalidade de uma eventual legalização. Esta última tática está amparada no princípio constitucional de que a iniciativa para a elaboração do orçamento é prerrogativa exclusiva do Executivo, não havendo base legal para o Legislativo intervir (cf. Sobottka et al., 2004).

Objetivos da oposição ficam claros em iniciativas legislativas como a do vereador oposicionista Isaac Ainhorn, de 1999. No artigo $2^{\circ}$ de seu projeto, ele coloca os poderes Executivo e Legislativo como co-promotores do debate 
anual obrigatório no processo de elaboração orçamentária, e no artigo $3^{\circ}$ eleva os delegados do Orçamento Participativo a parceiros do Legislativo enquanto elaboradores do plano de obras do município. Estes dois artigos evidenciam bem como, com a legalização, almejava-se mudanças nas relações de poder (cf. Processo Legislativo no $1181 / 99$ ).

Por outra parte, desde sua introdução, o Orçamento Participativo vem passando continuamente por modificações, seja por auto-regulação, seja por indução de parte do governo. Em 1993-1994 e 2000-2002, sob as duas gestões de Tarso Genro, ocorreram as reformas mais profundas. Por serem oportunas no contexto da temática em questão, três inovações do primeiro e uma do segundo período serão destacadas aqui. Destas, as mais abrangentes foram sem dúvida as do primeiro conjunto.

A despeito de uma forte vinculação -e, por vezes, até dependência- do Orçamento Participativo do Executivo municipal, em 1994 instituiu-se um regimento interno, no qual foram detalhados tanto procedimentos relativos à participação nas consultas sobre prioridades, como os critérios para a distribuição dos recursos entre as regiões da cidade. Este regimento é anualmente revisado no final do ciclo de trabalhos e a nova versão passa a valer para o ciclo seguinte.

Em sua fase inicial, o Orçamento Participativo recrutava a participação dos moradores exclusivamente a partir da área geográfica de sua residência nas regiões em que a cidade foi dividida. Mas algumas dificuldades levaram à busca de uma via complementar de recrutamento. Foi constatada, por exemplo, uma limitação dos foros regionais para alocar recursos em obras supraregionais. O Orçamento Participativo tinha um poder de atração muito seletivo; havia a necessidade de encontrar um espaço onde o poder público, lideranças políticas, técnicos e empresários pudessem debater prioridades transversais às regiões, como o sistema de transporte, a saúde, entre outros. Isso levou à criação, em 1994, de plenárias temáticas, paralelas às consultas aos moradores, onde grupos de interesse e políticos pudessem interagir.

Uma terceira inovação a destacar, introduzida em 1993, é a realização de congressos da cidade. Trata-se de processos consultivos e de debate sobre a cidade, que culminam em plenárias deliberativas. Estas deliberações não são vinculantes, mas orientam a administração municipal no encaminhamento de prioridades pelas vias institucionais consagradas, dando a elas uma ampla legitimação.

Por fim, uma quarta inovação a ser mencionada aqui, implementada a partir de 2001, é o uso da rede internet não só como fonte de informação, mas sobretudo como ferramenta para a participação no Orçamento Participativo. 
Trata-se de uma política que conjuga a criação de telecentros, onde a população mais pobre passa a ter acesso a salas públicas de internet, com a abertura do Orçamento Participativo para receber demandas e coletar votos de apoio a prioridades diretamente via rede. Em estudo recente, Freitas (2004) mostra que ainda há dificuldades a vencer para que esta iniciativa alcance plenamente seu objetivo de democratização do Orçamento Participativo consorciada com uma ampla política de inclusão digital de comunidades antes alijadas deste meio de comunicação. Não obstante isso, a abertura do Orçamento Participativo à participação direta de internautas oferece à população de todas as camadas sociais uma via de participação mais confortável que as plenárias presenciais. Caberá aos impulsionadores desta inovação encontrar formas de cativar esta participação.

A flexibilidade do Orçamento Participativo, por não ser preso a amarras legais e por ter assimilado diferentes níveis de estímulo e de processamento de auto-reflexão e crítica, faz com que mesmo os mais próximos simpatizantes e participantes sintam-se motivados a expressar suas criticas. Um grupo de trabalho instituído pela própria prefeitura municipal em 2001, por exemplo, num documento intitulado Rompendo nossos limites (Verle e Brunet, 2002), listou vários problemas e contradições. Alguns estudiosos/simpatizantes do Orçamento foram convidados a reagirem ao documento durante um seminário específico para avaliar o Orçamento Participativo de Porto Alegre, e acrescentaram outras tantas críticas e sugestões de melhoria (ibid.). Este permanente clima de negociação de possíveis mudanças no Orçamento Participativo completa o processo de cidadania local em Porto Alegre.

\section{Referências}

ALMEIDA, Maria Hermínia Tavares de. Federalismo e políticas sociais. In: Federalismo no Brasil, AFFONSO, R. d. B.; SILVA, P. L. B. (orgs.). São Paulo: Fundap, 1996, p. 13-40.

ANDREW, Caroline; GOLDSMITH, Michael. From local government to local governance - and beyond? International Political Science Review. v. 19, n. 2, 1998, p. 101-117.

AVRITZER, Leonardo; NAVARRO, Zander . A invoação democrática no Brasil: o orçamento participativo. São Paulo: Cortez, 2003.

COSTA, Sérgio. Dimensionen der Demokratisierung: Öffentlichkeit, Zivilgesellschaft und lokale Partizipation in Brasilien. Frankfut am Main: Vervuert, 1997.

DIAS, Marcia Ribeiro. Sob o signo da vontade popular: o orçamento participativo e o dilema da câmara municipal de Porto Alegre. Belo Horizonte: Ufmg, 2002..

FEDOZZI, Luciano. Orçamento participativo: reflexões sobre a experiência de Porto Alegre. Porto Alegre: Tomo, 1997. 
O poder da aldeia: gênese e história do orçamento participativo de Porto Alegre. Porto Alegre: Tomo, 2000.

FLEISCHER, David. The 2000 Brazilian local elections: a comparative analysis (1982-2000). Opin. Pública, v. 8, n. 1, maio 2002, p. 80-105.

FLEURY, Sônia. Estado sem cidadãos: seguridade social na América Latina. Rio de Janeiro: Fiocruz, 1994.

FLICKINGER, Hans-Georg. Em nome da liberdade. Porto Alegre: Edipucrs, 2003.

. Movimentos sociais e a construção do Político: Carl Schmitt. Civitas, Porto Alegre, v. 4, nº 1, jun. 2004.

FREITAS, Ilton. Telecentros Porto Alegre e as possibilidades de ampliação da democracia através da inclusão digital. Dissertação (mestrado). Porto Alegre: PPG em Ciências Sociais da Pucrs, 2004.

JOHNSTON, R. J.; Pattie, C. J.. Local government in local governance: the 1994-95 restructuring of local government in England. International Journal of Urban and Regional Research, v. 20, n. 1, 1996, p. 671-696.

KINZO, Maria D'Alva G. Partidos, eleições e democracia no Brasil pós-1985. Revista Brasileira de Ciências Sociais. v. 19, n. 54, 2004, p. 23-40.

LOPES, José Rogério. Mínimos sociais, cidadania e assitência social. Serviço Social e Sociedade, v, 19, n. 58, 1998, p. 94-108.

MARSHALL, T. H. Cidadania, classe social e status. Rio de Janeiro: Zahar, 1967.

NICOLAU, Jairo M. Dados eleitorais do Brasil: 1982-1996. Rio de Janeiro: Revan, 1998.

OFFE, Claus. Contradicciones en el estado del bienestar. Madrid: Alianza, 1990.

- Prinzipien sozialer Gerechtigkeit und die Zukunft des Sozialstaats. Forum Social Mundial, Porto Alegre, 2002.

SANTOS, Boaventura de Sousa (Org.). Democratizar a democracia: os caminhos da democracia participativa. Rio de Janeiro: Civilização Brasileira, 2002.

SARLET, Ingo Wolfgang (Org.). Direitos fundamentais sociais: estudos de direito constitucional, internacional e comparado. Rio de Janeiro: Ronovar, 2003.

SILVA, Marcelo Kunrath. Cidadania e exclusão: os movimentos sociais urbanos e a experiência de participação na gestão municipal em Porto Alegre. Porto Alegre: Editora da Ufrgs, 2002.

SOBOTTKA, Emil. Movimentos sociais: a busca da ampliação do espaço político. In: Entre caridade, solidariedade e cidadania: história comparativa do Serviço Social Brasil/Alemanha. In: FLICKINGER, H.-G. (Org.). Porto Alegre: Edipucrs, 2000.

SOBOTTKA, Emil A.; SAAVEDRA, Giovani A.; ROSA, Viviane da. Legalidade, legitimação e democratização no orçamento público estadual. In: STRECK, Danilo R.; EGGERT, Edla; SOBOTTKA, Emil A. Dizer a sua palavra. 2004 (no prelo)

SPOSATI, Aldaíza. Mínimos sociais e seguridade social: uma revolução da consciência da cidadania. Serviço Social e Sociedade. v. 18, n. 55,1997, p. 9-38. 
VERLE, João; BRUNET, Luciano (Org.). Construindo um novo mundo: avaliação da experiência do orçamento participativo em Porto Alegre - Brasil. Porto Alegre: Guayí, 2002.

UTZIG, Luís Eduardo. Notas sobre o governo do PT em Porto alegre. Novos Estudos Cebrap, v. 45, 1996, p. 209-222.

VIEIRA, Evaldo Amaro. As políticas sociais e os direitos sociais no Brasil: avanços e retrocessos. Serviço Social e Sociedade, v. 18, n. 53, 1997, p. 67-73.

Texto recebido em 15.01.2004 